\title{
Maximum Power Control of DFIG Based Grid Connected Wind Turbine Generator System
}

\author{
Muhammed Y. Worku ${ }^{1 *}$, M.A. Abido ${ }^{2}$, \\ ${ }^{1}$ King Fahd University of Petroleum and Minerals \\ Research Institute, Center for Engineering Research \\ Dhahran, Saudi Arabia \\ *Tel: +966-559713973, Fax: +966-138603535, email: muhammedw@kfupm.edu.sa \\ ${ }^{2}$ King Fahd University of Petroleum and Minerals \\ Department of Electrical Engineering \\ Dhahran, Saudi Arabia \\ Email: mabido@kfupm.edu.sa
}

\begin{abstract}
This paper presents a simulation model of variable speed wind turbine with a doubly fed induction generator developed in Matlab/simulink. Vector control of a doubly fed induction generator (DFIG) drive for variable speed wind power generation is described. A slip ring (wound rotor) induction generator with back to back three phase PWM converter between its rotor and the grid forms the electrical system. A vector control scheme for the PWM converters results in independent control of active and reactive power. Line (supply) voltage oriented reference frame has been used to independently control the active and reactive power. Results are provided at the end for subsynchronous and super-synchronous operation of the DFIG.
\end{abstract}

\section{Key words}

Wind energy conversion system (WECS), wound rotor induction machine, sub-synchronous generation, supersynchronous generation, vector control

\section{Introduction}

Renewable energy sources have recently received increased attention due to concerns about the environment and the search for alternate energy sources. The main advantages of electricity generation from renewable sources are the absence of harmful emissions and the in principle infinite availability of the prime mover that is converted into electricity. Wind energy conversion system (WECS) has proven to be a potential source for generation of electricity with minimal environmental impact. A Worldwide installed capacity of wind power is approximately 369,705 MW [1]. Squirrel cage and wound rotor Induction generators are the most commonly used generators for wind power application. Squirrel cage based WECS is shown in Fig. 1. In this setup the stator of the squirrel cage induction generator is connected to the grid by means of back-to-back connected power electronic converter bridges. Since the power converter has to convert all the stator power, the converter size depends on the stator power rating. The advantages of this configuration are its ability to make the best use of available wind power and the fact that it eliminates the need for a capacitor bank since it is able to draw its required reactive power from the grid. However, the cost of the power converter can be high due to its large size [2].

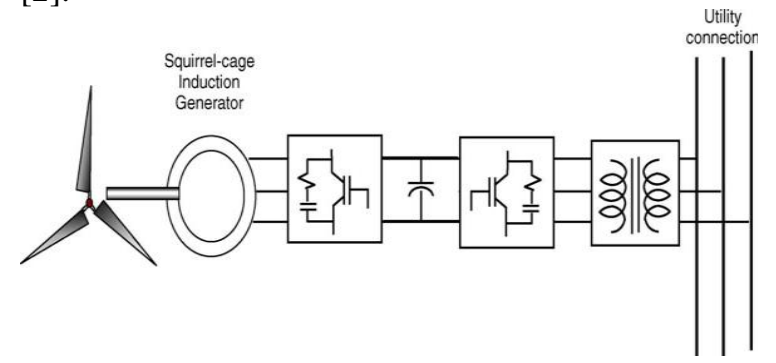

Fig.1 Variable Speed WECS with squirrel cage Induction Generator

The power converter size in the earlier system can be reduced by using it on the rotor side of a wound rotor induction generator to form a doubly fed induction generator (DFIG) as presented in Fig.2. The power converter is now connected between the rotor and grid. So it needs to carry only the slip power, the magnitude of which will be the machine slip times the stator power [23].

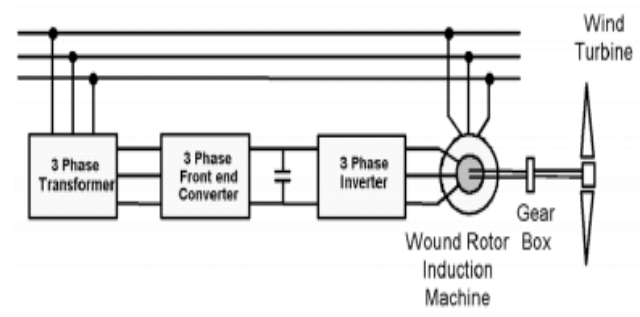


Fig 2 Variable speed WECS with wound rotor Induction Generator

The operating region of the DFIG in the torque-speed plane is shown in Fig.3. Since the rotor side control strategy becomes advantageous within a limited slip range, the operating region is spread out on both sides of the synchronous speed $\omega_{s}$, implying both sub-synchronous and super-synchronous modes of motoring and generating operations [4-8].

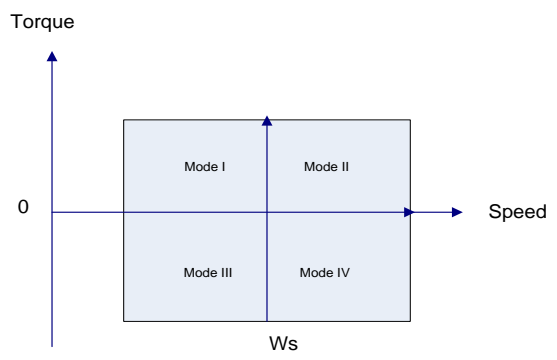

Fig. 3 Four Quadrant operating region with rotor side control

\section{System Modeling}

\section{A. Wind Turbine Model}

A wind turbine is a machine for converting the kinetic energy in wind into mechanical energy. The working principle of a wind turbine encompasses two main conversion processes. The turbine consists of a rotor that extracts kinetic energy from the wind and converts it into a rotating movement. This is then converted into electricity by a generator. Wind power generation using permanent magnet synchronous generator is presented in [9-10].

For a horizontal axis wind turbine, the amount of power $P_{m}$ that a turbine is capable of producing is given by [11-12]:

$$
P_{m}=\frac{1}{2} C_{p} \rho A V^{3}
$$

Where $P_{m}$ is the turbine mechanical power, $\rho$ is the density of the air in $\mathrm{kg} / \mathrm{m} 3, A$ is the exposed area in $\mathrm{m}^{2}, V$ is the velocity in $\mathrm{m} / \mathrm{s}$ and $C_{p}$ is called the power coefficient and gives the fraction of the kinetic energy that is converted into mechanical energy by the wind turbine. It is a function of the tip speed ratio $\lambda$ and depends on the blade pitch angle for pitch-controlled turbines. The tip speed ratio may be defined as the ratio of turbine blade linear speed and the wind speed:

$$
\lambda=\frac{W_{t} R}{V}
$$

Where $R$ is the radius of the turbine and $\omega_{t}$ is the turbine rotational speed.

A typical relationship between $C_{p}$ and $\lambda$ (for maximum pitch angle) is shown in Fig. 4 [11-13]. It is clear from this figure that there is a value of $\lambda$ for which $C_{p}$ is maximized thus maximizing the power for a given wind speed.

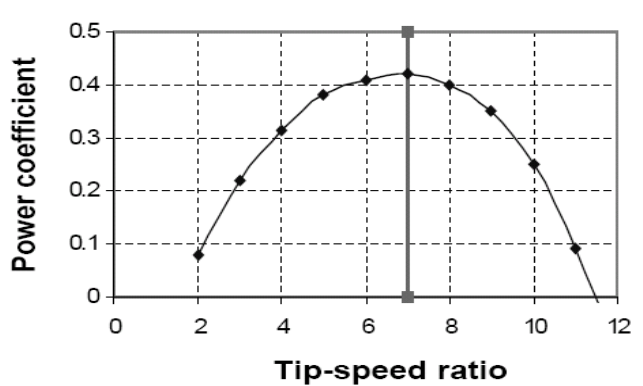

Fig. $4 C_{p}$ vs $\lambda$ characteristics for 0 pitch angle

Because of the relationship between $C_{p}$ and $\lambda$, as the turbine speed changes for a given wind velocity there is a turbine speed that gives a maximum output power. This is shown in Fig. 5 for various wind speeds [14]. As seen in the figure the peak power for each wind speed occurs at the point where $C_{p}$ is maximized. The prime motivation for variable speed control of WECS is to track the rotor speed with changing wind velocity so that is always maintained at its maximum $C_{p}$ value. To maximize the power generated it is therefore desirable for the generator to have a power characteristic that will follow the maximum $C_{p}$ line.

\section{POWER}

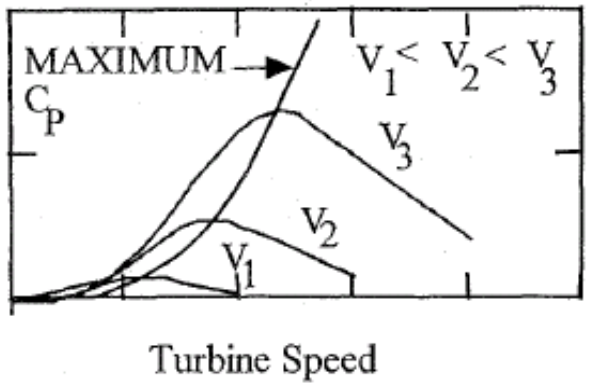

Fig.5 Typical Turbine power relationship for various wind speeds

\section{Proposed Controller}

Variable speed operation of the wind turbine can be realized by appropriate adjustment of the rotor speed and pitch angle. For a variable speed wind turbine with a doubly fed induction machine, it is possible to control the load torque at the generator directly, so that the speed of the turbine rotor can be varied within certain limits. An advantage of the variable speed wind turbine is that the rotor speed can be adjusted in proportion to the wind speed in low to moderate wind speeds so that the optimal tip speed ratio is maintained. At this tip speed ratio the aerodynamic efficiency, $C_{p}$, is at maximum, which means that the energy conversion is maximized.

In general, variable speed wind turbines may have two different control goals, depending on the wind speed. In low to moderate wind speeds, the control goal is maintaining a constant optimum tip speed ratio for maximum aerodynamic efficiency. In high wind speeds, the control goal is to keep the rated output power fixed in order not to overload the system [15-19]. Vector control scheme for the DFIG is depicted in Fig. 6. 


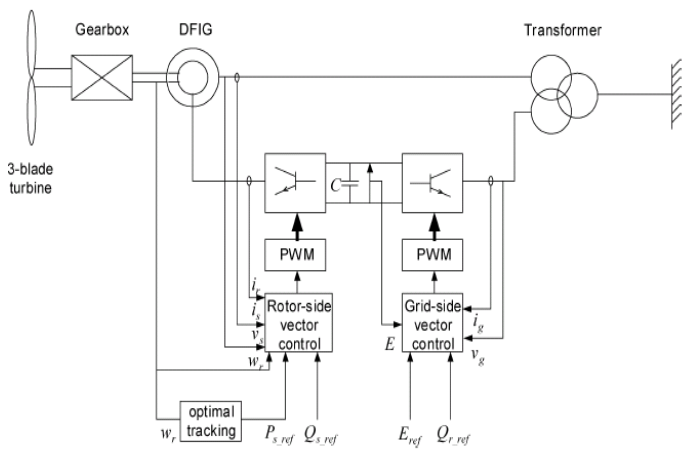

Fig.6 Vector control scheme for DFIG

Two voltage-fed PWM converters are inserted in the rotor circuit, with the supply-side PWM converter connected to the stator/supply via three single- phase chokes. The voltage-transfer characteristics of the system, including the three phase back-to-back PWM converters, are given approximately by:

$$
\begin{aligned}
& V_{s}=m_{1} \frac{\sqrt{3} E}{2 \sqrt{2}} \\
& V_{r}= \pm s \frac{V_{s}}{n}=m_{2} \frac{E}{2 \sqrt{2}} \\
& s= \pm \frac{n m_{2}}{\sqrt{3} m_{1}}
\end{aligned}
$$

Where $n$ is the stator-rotor turns ratio of the DFIG, $s$ is the slip and $m_{1}, m_{2}$ are the PWM modulation depths of the stator-side and rotor side converters respectively.

Eqn. (3) determines the speed range of the generator. For wind generation, a restricted speed range is acceptable on account of a minimum wind velocity (the cut-in speed), below which very little energy is extractable. The generator speed corresponding to rated wind velocity can be set at any point by the choice of gearbox ratio. Of course, to get the maximum benefit from the Scherbius scheme, this point should be well above synchronous speed where power is extracted from both the rotor and stator of the machine. Eventually, however, as the slip is increased, the system efficiency starts to decrease since more power passes through the DC link converters and the rotor iron and frictional losses increase.

\section{A. Grid (Supply) Side Converter Control}

The objective of the vector-control scheme for the gridside PWM converter is to keep the DC-link voltage constant regardless of the magnitude and direction of the rotor power, while keeping sinusoidal grid currents. Decoupled control of active and reactive powers flowing between rotor and grid is done by using supply voltage vector oriented control $\left(d^{e}-q^{e}\right)$. All voltage and current quantities are transformed to a special reference frame that rotates at the same speed as the supply voltage space phasor with the real axis ( $d$-axis) of the reference frame aligned to the supply voltage vector. At steady state, the reference frame speed equals the synchronous speed. In such a scheme, current $i_{g d}^{e}$ is controlled to keep the dc link voltage constant and current $i_{g q}^{e}$ is used to obtain the desired value of reactive power flow between the supply side converter and the supply. It may also be responsible for controlling reactive power flow between the grid and the grid side converter by adjusting $Q_{r, r e f}$.

The scheme makes use of the supply voltage angle determined dynamically to map the supply voltage, the converter terminal voltage and the phase currents onto the new reference frame. First the supply voltage angle $(\theta)$ has to be determined.

By definition, the supply voltage angle is:

$$
\theta=\tan ^{-1}\left(\frac{V_{s q}}{V_{s d}}\right)
$$

Aligning the $d$-axis of the reference frame along the supply-voltage position, $V_{s q}^{e}=0$, and, since the amplitude of the supply voltage is constant $V_{s d}^{e}$ is constant. The active and reactive power will be:

$$
\begin{aligned}
& P_{g c}=\frac{3}{2}\left(V^{e}{ }_{s d} i_{g d}^{e}+V^{e}{ }_{s q} i_{g q}^{e}\right)=\frac{3}{2}\left(V^{e}{ }_{s d} i_{g d}^{e}\right) \\
& Q_{g c}=\frac{3}{2}\left(V^{e}{ }_{s q} i_{g d}^{e}-V^{e}{ }_{s d} i_{g q}^{e}\right)=-\frac{3}{2}\left(V^{e}{ }_{s d} i_{g q}^{e}\right)
\end{aligned}
$$

The dc power has to be equal to the active power flowing between the grid and the grid side converter. Thus,

$$
\begin{aligned}
& E i_{o s}=\frac{3}{2}\left(V^{e}{ }_{s d} i_{g d}^{e}\right) \\
& C \frac{\partial E}{\partial t}=i_{o s}-i_{o r}
\end{aligned}
$$

Where, $i_{o s}$ is the current between the dc link and the stator and $i_{o r}$ is the current between the dc link and the rotor. Thus, the dc link voltage can be controlled by controlling $i_{g d}^{e}$.

The control scheme thus utilizes current control loops for $i_{g d}^{e}$ and $i_{g q}^{e}$ with the $i_{g d}^{e}$ demand being derived from the DC-link voltage error through a standard PI controller as shown in Fig.7. The current $i_{g q}^{e}$ reference was forced to zero so as to make the displacement equal to zero.

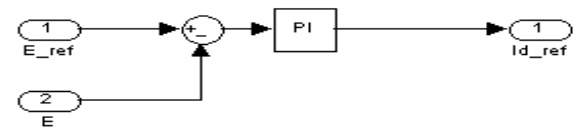

Fig.7. Reference current from DC link voltage error

\section{B. Rotor-Side Converter Control}

The vector-control scheme for the rotor-side PWM converter ensures decoupling control of stator-side active and reactive power drawn from the grid. To exploit the advantages of variable speed operation, the tracking of optimum torque-speed curve is essential. Speed can be adjusted to the desired value by controlling torque. So, an approach of using active power set point from the instantaneous value of rotor speed and controlling the rotor current $i_{r d}^{e}$ in line voltage reference frame to get the desired active power will result in obtaining the desired values of speed and torque according to the optimum torque speed curve. The reference value of the stator-side active power is obtained via a look-up table for a given generator rotor speed, which enables the optimal power 
tracking for maximum energy capture from the wind. Normally, the reference values of both stator-side and rotor side reactive power, $Q_{\text {sref }}, Q_{\text {rref }}$ and are all set to zero to ensure unity power factor operation of the studied wind turbine.

Using the same approach like the grid side converter, the stator and rotor currents are transformed to the new reference frame using the voltage angle calculated in eqn. (4).

Stator flux linkage expressed in the new reference frame:

$$
\begin{aligned}
& \lambda^{e}{ }_{s d}=L_{s} i^{e}{ }_{s d}+L_{m} i_{r d}^{e} \\
& \lambda^{e}{ }_{s q}=L_{s} i^{e}{ }_{s q}+L_{m} i_{r q}^{e}
\end{aligned}
$$

Where, $\mathrm{L}_{\mathrm{s}}=\mathrm{L}_{1 \mathrm{~s}}+\mathrm{L}_{\mathrm{m}}$

Aligning the $d$-axis of reference frame to be along the line voltage will result in:

$\lambda_{\text {sd }}^{\mathrm{e}}=0$ and neglecting stator resistance will lead to $V_{s q}=0$. Substituting for $V_{s q}=0$, the active and reactive power will be simplified as follows:

$$
\begin{aligned}
& P_{s}=\frac{3}{2}\left(V^{e}{ }_{s d} i^{e}{ }_{s d}+V^{e}{ }_{s q} i_{s q}^{e}\right)=\frac{3}{2}\left(V^{e}{ }_{s d} i^{e}{ }_{s d}\right) \\
& Q_{s}=\frac{3}{2}\left(V^{e}{ }_{s q} i^{e}{ }_{s d}-V^{e}{ }_{s d} i^{e}{ }_{s q}\right)
\end{aligned}
$$

Therefore, the above equations show that active and reactive powers of the stator can be controlled independently.

From Eqn. 7,

$$
\begin{gathered}
\lambda^{e}{ }_{s d}=L_{s} i_{s d}^{e}+L_{m} i_{r d}^{e}=0 \\
i_{s d}^{e}=\frac{-L_{m}}{L_{s}} i_{r d}^{e}
\end{gathered}
$$

Substituting for $i_{d s}^{e}$ into the torque and active power equation will result in:

$$
P_{s}=\frac{3}{2}\left(V^{e}{ }_{s d} i_{s d}^{e}\right)=-\frac{3}{2} \frac{L_{m}}{L_{s}}\left(V^{e}{ }_{s d} i_{r d}^{e}\right)
$$

The stator magnetizing current is

$$
\begin{aligned}
& \underset{i_{m s}}{\longrightarrow}=\frac{\lambda^{e}{ }_{s d}+j \lambda^{e}{ }_{s q}}{L_{m}} \\
& \underset{i_{m s}}{\longrightarrow}=\frac{j \lambda_{s q}}{L_{m}}
\end{aligned}
$$

Thus, $\stackrel{i_{m s}}{\longrightarrow}=\left|i_{m s}\right|_{\text {is a constant value. }}$

From Eqn. 7,

$$
\begin{gathered}
i_{s q}=\frac{\lambda_{s q}-L_{m} i_{r q}}{L_{s}}=\frac{L_{m}}{L_{s}}\left(\left|i_{m s}\right|-i_{r q}\right) \\
Q_{s}=\frac{-3}{2}\left(V_{s d} i_{s q}\right)=\frac{-3}{2} \frac{l_{m}}{L_{s}} V_{s d}\left(\left|i_{m s}\right|-i_{r q}\right)
\end{gathered}
$$

Thus, the variations in rotor currents will also reflect in the variation of stator side currents, $i_{s d}^{e}, \mathrm{i}_{\mathrm{sq}}^{\mathrm{e}}$ and hence in the stator side real and reactive powers also. This principle has been used in the control of stator real and reactive powers.
The control scheme uses a PI controller to obtain the reference value for $i_{r d}^{e}$ from real power error that is the difference between desired and actual values of real power. Similarly, a PI controller can be tuned to get the reference value for $i_{r q}^{e}$ from the reactive power error. Then, both reference currents were transformed to their natural reference frame that is the rotor frame. These rotor current references, after a $d q$-to- $a b c$ transformation, were used for implementing the technique on the rotor side three-phase converter.

\section{Results and Discussions}

This study is made with simulation on the Matlab/Simulink and Power System Block Set modules. The induction machine is modelled on the stationary reference frame. With stationary reference frame, the speed of the reference frame is equal to zero. Stator and rotor voltage equation, flux linkage equation and torque equation are utilized for modelling in term of $q$ component, $d$ component and zero component. Stator and rotor circuits are assumed to be star connected. In addition, all rotor parameters are transformed to stator side via stator-rotor turns ratio (in this study a turn ratio of 1 is assumed).

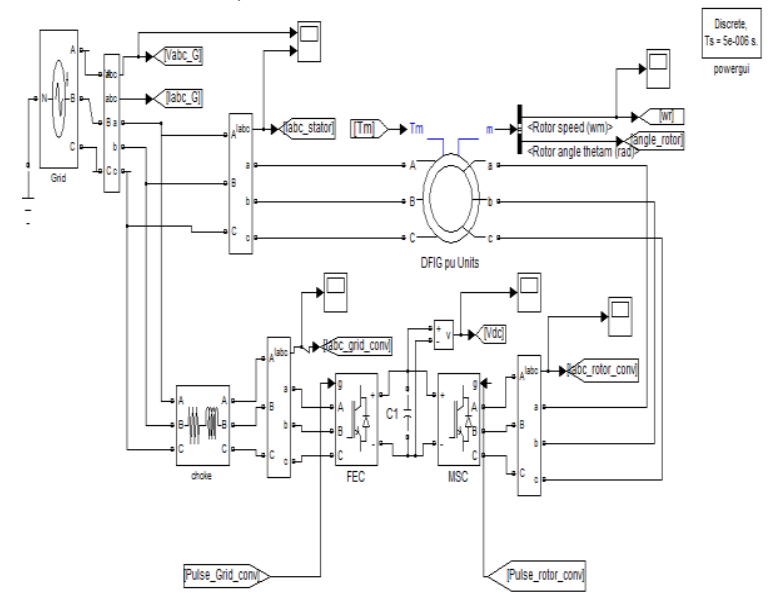

Fig.8 Simulink model of Grid connected DFIG

The tracking characteristic obtained through a look up table for different turbine speed $\omega_{r}$ by interpolationextrapolation is shown Fig. 9.

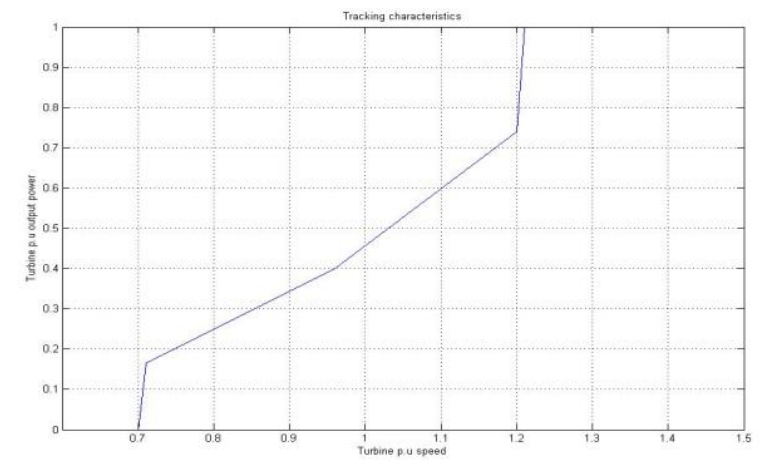

Fig. 9. Tracking characteristics

\section{A. Sub-synchronous generation}

Figures 10 to 17 show response of the system for such application. Fig. 10 shows that the measured active 
power at the grid terminal and the reference active power from the optimal tracking are the same at steady state. Output Torque $\left(\mathrm{T}_{\mathrm{m}}\right.$,) from the wind turbine and reference active power $\left(P_{\text {sref }},\right)$ from optimal power tracking is depicted in Fig. 11. The pitch angle is kept constant at its maximum value (zero) for sub-synchronous generation where the output power is below the rated value as shown in Fig. 12. The DC link voltage is held constant by the grid side converter controller as presented in Fig. 14. The measured reactive power and the reference reactive power are both zero at steady state as seen Fig. 15. The stator voltage and current are shown in Fig. 16.

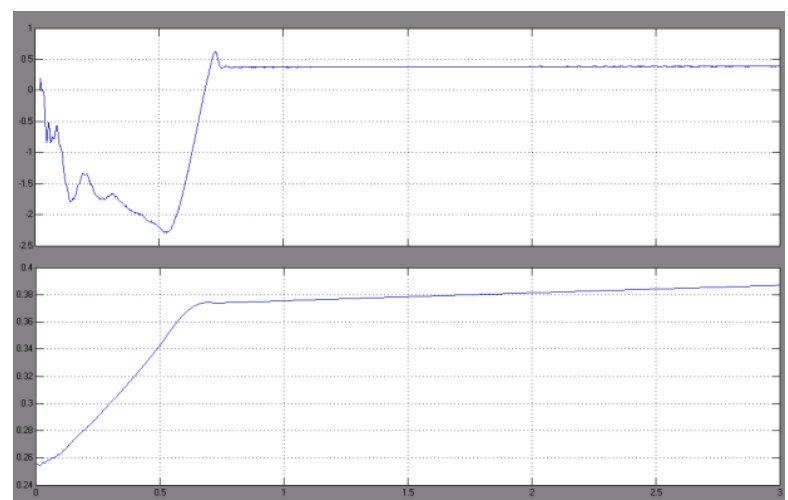

Fig. 10 Actual active power $\left(P_{s}\right.$, upper) and reference active power $\left(P_{\text {sref }}\right.$, lower)

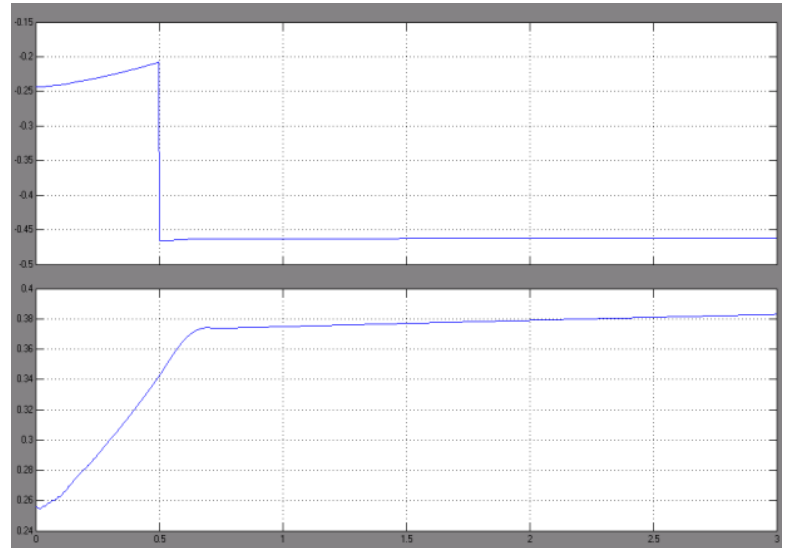

Fig. 11 Output Torque ( $T_{m}$, upper) and reference active power $\left(P_{\text {sref }}\right.$, lower $)$

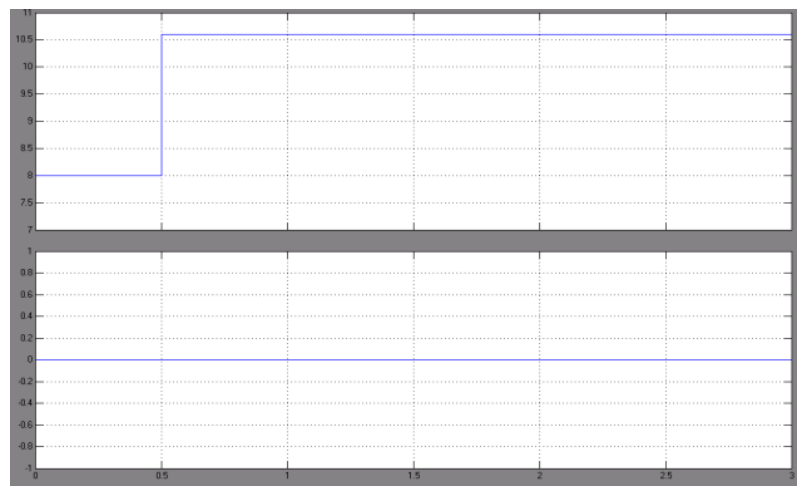

Fig. 13 Wind speed (upper) Vs pitch angle (lower)

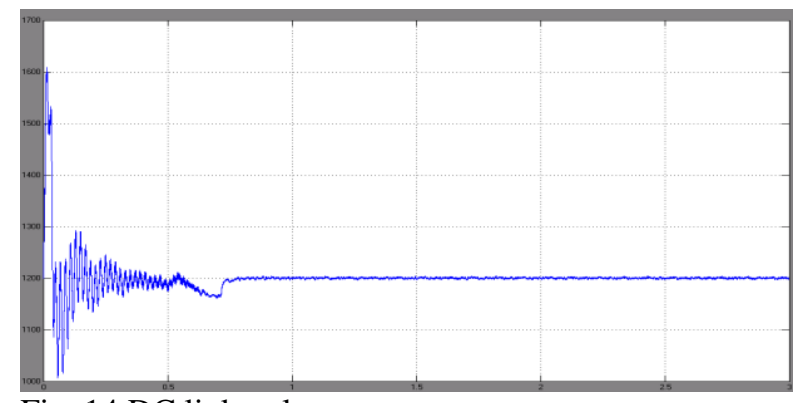

Fig. 14 DC link voltage

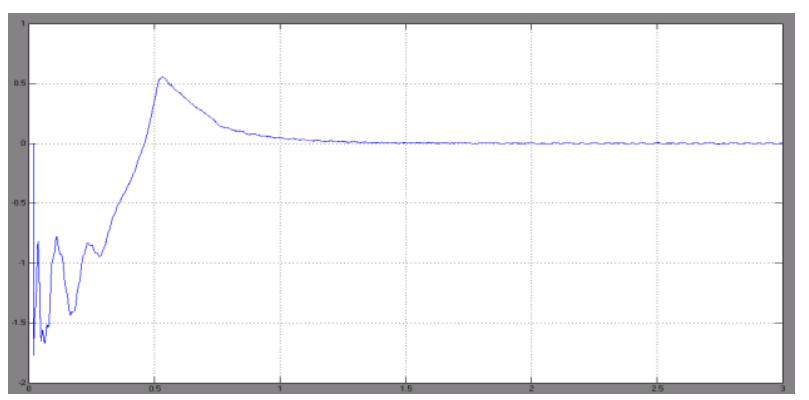

Fig. 15 Actual reactive power $Q_{s}$ when reference reactive Power $\left(Q_{\text {sref }}\right)$ is zero

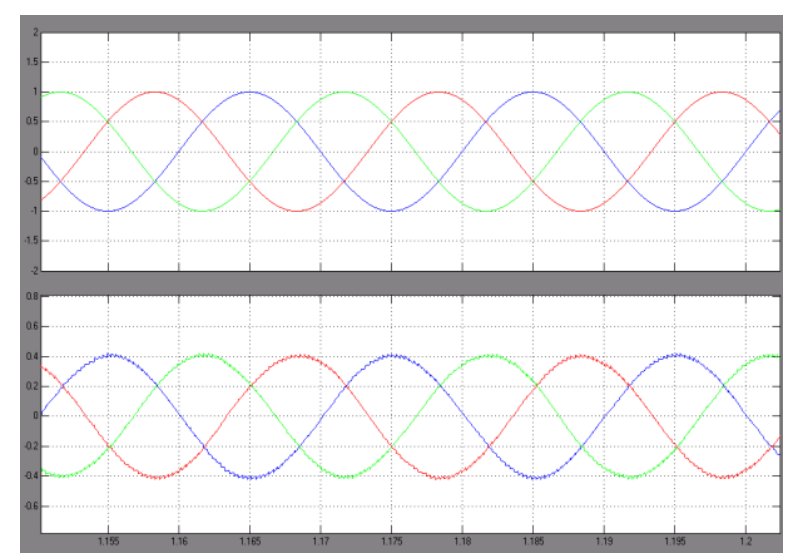

Fig.16. Stator voltage (upper) and current (lower)

\section{B. Super-synchronous generation}

Figure 17 and 18 show the response of the system for super-synchronous generation. As depicted in Fig. 17, the output torque is limited because the pitch angle is called in to action since from the tracking characteristics (Fig.9) the output power corresponding to the wind speed is above the rated value. Fig. 18 shows that the pitch angle control is called in to action when the generator speed is above 1.21 p.u. The pitch angle limits the output power and torque. 


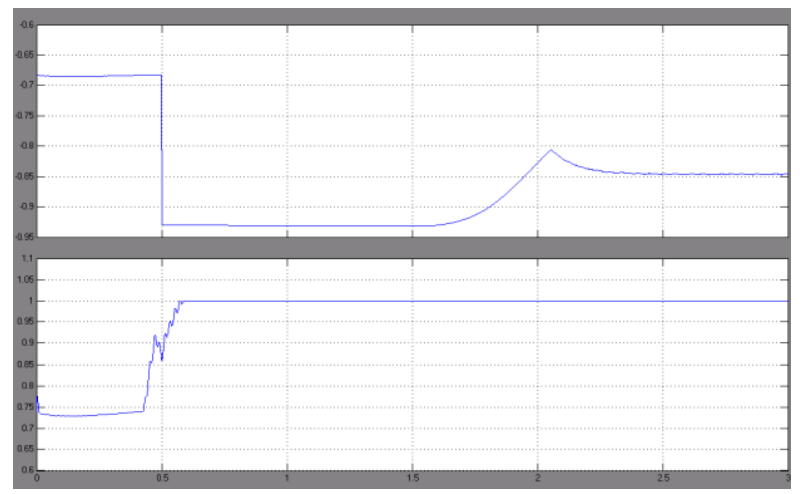

Fig. 17 Output torque ( $T_{m}$, upper) and reference active power $\left(P_{\text {sref }}\right.$, lower $)$

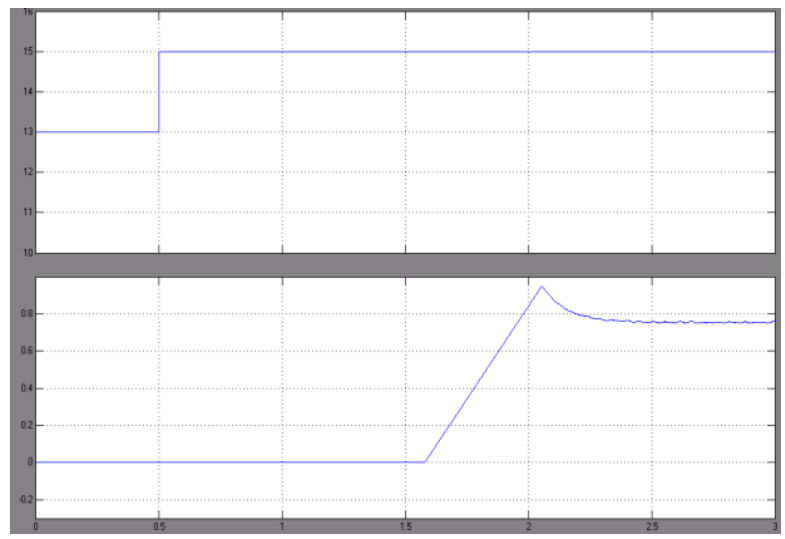

Fig. 18 Wind speed (upper) vs pitch angle (lower)

\section{Conclusion}

It is shown that a variable speed system using wound rotor induction machine controlled from the rotor side is superior because of higher energy output, lower rating (hence, lower cost) of converters, and better utilization of a generator when compared to systems using a cage rotor induction machine with the same rating. It has been shown from the simulation results that, using vector control, the reference active power from the wind and the measured active power at the grid terminals are equal both at subsynchronous and super-synchronous speed operation. In order to limit the energy capture above the rated value pitch control has been implemented to the system and Simulation results show that the controller maintains the extracted energy till the rated value of the wind turbine mechanical power output.

\section{Acknowledgment}

The authors acknowledge the support provided by the Deanship of Scientific Research, King Fahd University of Petroleum \& Minerals, through Electrical Power and Energy Systems Research Group funded project \# RG1420-1\&2.

\section{References}

[1] http://www.gwec.net/global-figures/graphs/

[2] Rajib Datta, V. T. Ranganathan "Variable-Speed Wind Power Generation Using Doubly Fed Wound Rotor Induction Machine-A Comparison with Alternative Schemes" IEEE Transactions on Energy Conversion, Vol. 17, No. 3, September 2002

[3] Alan Mullane, Mark O'Malley "The Inertial Response of Induction- Machine- Based Wind Turbines" IEEE
Transactions on Power Systems, Vol. 20, No. 3, August 2005

[4] L. Cadirci, M. Ermiq "Double-output induction generator operating at Sub synchronous and super synchronous speeds: steady-state performance optimization and windenergy recovery" IEE Proceedings-B, Vol. 139, No. 5, September 1992

[5] Debiprasad Panda 1, Thomas .A.Lipo "Double side control of wound rotor induction machine for wind energy application employing half controlled converters" IEEE Transactions on Energy Conversion, 2005

[6] Debiprasad Panda, Eric L. Benedict, Giri Venkataramanan, Thomas A. Lipo" A Novel Control Strategy for the Rotor Side Control of a Doubly-Fed Induction Machine" 2001 IEEE

[7] B. Rabelo, W. Hofmann, "Power Flow Optimization and Grid Integration of Wind Turbines with the Doubly-Fed Induction Generator" IEEE Transactions on Energy Conversion, 2005

[8] Mohammad Jafar Zandzadeh, Abolfazl Vahedi, "Modeling and improvement of direct power control of DFIG under unbalanced grid voltage condition", Electrical Power and Energy Systems, 59, 58-65, 2014.

[9] Muhammed Y. Worku, "Power Smoothing Control of PMSG Based Wind Generation Using Supercapacitor Energy Storage System", International Journal of Emerging Electric Power Systems. 2017; 20160181

[10] Muhammed Y. Worku, M. A. Abido, and R. Iravani, " PMSG based wind system for real-time maximum power generation and low voltage ride through", Journal of Renewable Sustainable Energy 9, 013304 (2017); doi: 10.1063/1.4976141

[11] P.W. Carlin, A.S. Laxson, E.B. Muljadi, "The History and State of the Art of Variable-Speed Wind Turbine Technology" National Renewable Energy Laboratory, February 2001

[12] Muhammed Yibre and M. A. Abido, "Supercapacitors for wind power application", International Conference on Renewable Energy Research and Applications, Madrid, Spain, 20-23 October 2013.

[13] Lihui Yang, Zhao Xu, Jacob ostergaard, Zhao Yang Dong, and Kit Po Wong, "Advanced Control Strategy of DFIG Wind Turbines for Power System Fault Ride Through", IEEE TRANSACTIONS ON POWER SYSTEMS, Vol 27, No. 2, May 2012.

[14] Andrew Miller, Edward Muljadi, Donald S. Zinger "A Variable Speed Wind Turbine Power Control" IEEE Transactions on Energy Conversion, Vol. 12, No.2, June 1997

[15] Muhammed H. Rashid "Power Electronics Circuits, Devices, and Applications" Pearson Education, Third edition 2004

[16] E. Muljadi, K. Pierce, P. Migliore" Control Strategy for Variable-Speed, Stall-Regulated Wind Turbines" Presented at American Controls Conference Philadelphia, PA June 24-26, 1998

[17] E. Muljadi, C.P. Butterfield "Pitch-Controlled VariableSpeed Wind Turbine Generatio "Presented at the 1999 IEEE Industry Applications Society Annual Meeting Phoenix, Arizona October 3-7, 1999

[18] Alexander Helmedag, Timo Isermann, and Antonello Monti, "Fault Ride Through Certification of Wind Turbines Based on a Hardware in the Loop Setup", IEEE Transactions on Instrumentation and Measurement, Vol 63, No. 10, October 2014.

[19] Tao Sun, Zhe Chen, Frede Blaabjerg, "Flicker Study on Variable Speed Wind Turbines with Doubly Fed Induction Generators" IEEE Transactions on Energy Conversion, Vol. 20, No. 4, December 2005. 